\title{
Flexibilização organizacional e empregabilidade individual: proposição de um modelo explicativo
}

\author{
Diogo Henrique Helal
}

\section{Resumo}

Este artigo explora a temática da empregabilidade individual no contexto atual de flexibilidade organizacional, procurando ampliar a discussão sobre 0 assunto, centrada na teoria do capital humano. Tal ampliação se faz necessária pela complexidade e multicausalidade do fenômeno em questão. Assim, esta análise propõe um modelo explicativo da empregabilidade individual, baseada em profunda revisão bibliográfica, buscando um melhor entendimento sobre 0 que determina 0 acesso ao emprego. 0 modelo é concebido com base em três abordagens: na teoria do capital humano, na teoria do capital cultural e na teoria do capital social. São apresentadas também sugestões para a operacionalização das variáveis, tornando o modelo plenamente aplicável. Obviamente, a proposição do modelo não esgota as investigações sobre o tema. Trata-se de um esforço para conhecer melhor as linhas gerais do fenômeno. A discussão teórica permitiu ver que o mercado de trabalho deve ser estudado como algo inserido em um contexto social, no qual variáveis nãomeritocráticas, como aquelas ligadas ao capital cultural e social de um indivíduo, são valorizadas. Tal conclusão pode reorientar as políticas públicas direcionadas ao mercado de trabalho, assim como as políticas de recursos humanos adotadas pelas organizações.

Palavras-chave: flexibilidade organizacional; capital humano; capital cultural; capital social

\begin{abstract}
The article explores the thematic of the individual employability in the current context of organizational flexibility, aiming to extend the current quarrel on the subject, centered in the theory of the human capital. Such extent becomes necessary in function of the multicausality of the phenomenon in question. This article suggests an explaning model of the individual employability, based upon a deep bibliographical revision, with the intention of searching a better agreement on what it determines the access to the job. The model is conceived on the basis of the theories of human, cultural and social capitals. Suggestions for the operacionalization of the variables are presented, making the model applicable. The proposal of the model does not put an end to the studies on the subject. This article is about an effort to better know the general lines of the phenomenon. The theoretical quarrel allowed to see that the job market must be studied as something inserted in a social context, in which non-meritocratics variables are valued. Such conclusion can redirect the public policies directed to the job market, as well as the policies of human resources adopted by the organizations.
\end{abstract}

Keywords: organizational flexibilization; human capital; employability; cultural capital; social capital

\section{Introdução}

O século XX, particularmente em seus últimos anos, foi um período de profundas mudanças na sociedade e na economia de diversos países, em especial do Brasil. Desde meados da década de 1970, o país vem vivendo a intensificação dos processos de urbanização e industrialização da sua economia; resultado, principalmente, do esgotamento do modelo fordista de produção e organização do trabalho, o que impulsionou o surgimento de novas bases institucionais para o desenvolvimento do capitalismo (baseado em modelos flexíveis de produção, com destaque para o capital financeiro).

\footnotetext{
" Professor Assistente do UNI-BH (Centro Universitário de Belo Horizonte) e do Centro Universitário UNA. Doutorando em Ciências Humanas: Sociologia e Política (FAFICH/UFMG),

Artigo recebido em junho de 2004 e aprovado em agosto de 2004.
} 
Sob essa nova égide, as empresas iniciaram um processo de reestruturação, centrado em uma nova revolução tecnológica, de base microeletrônica. Esse momento ficou marcado pela difusão de um novo padrão tecnológico que possibilitou a passagem da fase de mecanização e automação rígida (característica do modelo fordista de produção) para a fase de automação flexível (PIORE e SABEL, 1984), própria do modelo pósfordista.

Para Castells (1999), essa revolução tecnológica, centrada nas tecnologias da informação, está remodelando a base material da sociedade em ritmo acelerado. Economias por todo o mundo passaram a manter interdependência global, apresentando uma nova forma de relação entre a economia, o Estado e a sociedade, em um sistema de geometria variável

Tal processo causou forte impacto no mercado de trabalho em todo o Brasil, que, segundo Pochmann (2001), vive um momento de desestruturação. Para o autor, os novos conhecimentos científicos e tecnológicos se associaram às exigências empresariais de contratação de empregados com polivalência multifuncional, maior nível de motivação e habilidades laborais adicionais no exercício do trabalho.

A força de trabalho brasileira mudou de uma situação inicial de forte dependência em relação a atividades agropecuárias para uma diversificada estrutura ocupacional urbana. Recentemente, nos anos 1990, mergulhou em um acelerado processo de informalização e precarização do trabalho, o que vem gerando uma profunda modificação na qualidade da ocupação gerada no país.

Os novos postos de trabalho, que estão surgindo em função das transformações das tecnologias e da divisão internacional do trabalho, não oferecem, em sua maioria, ao eventual ocupante, as compensações usuais que as leis e contratos coletivos vinham garantindo (SINGER, 2000, p.24).

Trata-se da migração de contingentes de trabalhadores formais para as ocupações informais; ocupações que não oferecem à mão-de-obra proteções sociais e trabalhistas. ${ }^{1}$

Percebe-se claramente que a globalização e as políticas neoliberais vêm transformando o mercado de trabalho e a estrutura ocupacional no Brasil e em diferentes países; tema que vem sendo abordado por diversos e importantes estudos (PRYOR e SCHAFFER, 1999). No Brasil, entretanto, com exceção das abordagens econômicas, poucos são as pesquisas a respeito (PASTORE e SILVA, 2000; SANTOS, 2002).

Sobre esse processo de flexibilização do trabalho e seu impacto na mão-de-obra brasileira, um dos pontos que merece ser melhor estudado e analisado refere-se à empregabilidade dos indivíduos. Esse assunto é fonte de amplos debates; principalmente, por não haver um consenso sobre o que realmente determina o acesso dos indivíduos ao emprego no país.

A teoria do capital humano, de origem econômica neoclássica, (BECKER, 1964; MINCER, 1974) propôs há muito uma explicação para esse tema. Para seus teóricos, quanto maior o estoque de capital humano de um indivíduo, maior sua produtividade marginal e mais elevado, portanto, será seu valor econômico no mercado de trabalho e conseqüentemente sua empregabilidade.

O mais importante nesta discussão, na verdade, é lembrar que a empregabilidade é um fenômeno complexo e determinado por diversos fatores. Assim, não se pode imaginar que as oportunidades de emprego são determinadas apenas pelos elementos ligados ao capital humano do indivíduo (as habilidades cognitivas, experiência etc.). Basear as explicações teóricas sobre esse tema somente nesse aspecto seria incorrer em um reducionismo imperdoável.

Nesse sentido, apresenta-se como questão fundamental a compreensão de quais são os fatores que, de fato, influenciam o acesso ao emprego, e de que forma se dá essa influência. Para tanto, este estudo propõe um modelo teórico que visa apresentar as linhas gerais do fenômeno da empregabilidade individual, em função das

\footnotetext{
${ }^{1}$ Como bem registram Neves, Dourado e Fernandes (1999), há, muitas vezes, no setor informal, empregos melhores do que muitos existentes no setor
} formal. Contudo, no geral, os empregos formais oferecem condições melhores (salário, estabilidade) do que empregos informais. 
novas exigências e configurações do mercado de trabalho. A empregabilidade é aqui tratada como um fenômeno complexo, determinado por diversos fatores. Dos aspectos relacionados ao fenômeno, este artigo destaca aqueles ligados ao capital humano, cultural e social. A inclusão de variáveis não-meritocráticas, como aquelas ligadas ao capital cultural e social do indivíduo, torna a explicação do modelo pertinente à realidade brasileira, uma vez que tal realidade possui como uma de suas principais características o personalismo nas relações (FREITAS, 1997). A proposição desse modelo, com base em variáveis não-meritocráticas, também se mostra condizente com a atual discussão acerca das competências. Tal noção representa, para Ferretti (1997), a atualização do conceito de qualificação (próprio do fordismo), segundo as perspectivas do capital, tendo em vista adequá-lo às novas formas pelas quais este se organiza para obter maior e mais rápida valorização. Ramos (2001), por sua vez, afirma que segundo esse novo modelo de formação (o de competências), o indivíduo passa de uma lógica "de ter" para uma "de ser". Tal contexto passa então a exigir do trabalhador uma constante atualização, flexibilização e adaptabilidade diante das novas demandas do mundo do trabalho. Exige-se do trabalhador um tipo de conhecimento não restrito apenas ao técnico-operacional, e sim àquele que envolva atitude, habilidades de comunicação e traços de personalidade. Diante dessas novas exigências, é de se esperar que a empregabilidade do indivíduo passe a ser influenciada por outros aspectos que não os meritocráticos, ligados ao capital humano, como, dentre outros o seu estoque de capital cultural e social.

O modelo explicativo da empregabilidade aqui apresentado está então baseado em três abordagens teóricas: teoria do capital humano (BECKER, 1964; MINCER, 1974), teoria do capital cultural (BOURDIEU e PASSEROM, 1977; BOURDIEU, 1979; BOURDIEU, 1987) e teoria do capital social (BOURDIEU, 1980; BURT, 2000; COLEMAN, 1988; 1994; GRANOVETTER, 1973, 1985; 1995; PORTES, 1998; PUTNAM, 2000). Com base nessa discussão teórica, este artigo propõe um modelo explicativo para a empregabilidade individual, bem como sugere caminhos para sua operacionalização, visando ampliar o debate sobre o tema, tornando-o mais pertinente com a atual realidade organizacional.

\section{Empregabilidade}

A palavra empregabilidade ocupa posição de destaque na academia, no mundo empresarial e na discussão sobre políticas públicas, seja no Brasil ou em outros países. Seu surgimento, entretanto, é recente. É reflexo do agravamento da crise pela qual passa o mercado de trabalho em todo mundo, em função da diminuição do número de empregos formais e do aumento dos níveis de desemprego e do trabalho informal. O desemprego que assola vários países foi o que realmente trouxe o tema para a ordem do dia. "Frente a este quadro é natural que os governos e as classes dominantes se defrontem com o dilema da gestão dos não-empregáveis. Estão em discussão diferentes fórmulas, seja de aposentadoria precoce (...) seja de renda mínima para integrantes da PEA ou de subsídios e garantias ao trabalhador precarizado" (PAIVA, 2000, p.54).

Vale lembrar, contudo, que a atual conjuntura do mercado de trabalho é produto do processo de reestruturação econômica iniciado a partir da década de 1970, com o esgotamento do modelo fordista de produção. Dessa forma, a preocupação com a empregabilidade é, na verdade, resultado das novas exigências feitas aos trabalhadores, por parte das organizações, sob a égide do novo modo de acumulação capitalista, conhecido como pós-fordismo ou modo de acumulação flexível.

A acumulação flexível é marcada por um confronto direto com a rigidez do fordismo. Ela se apóia na flexibilidade dos processos de trabalho, dos mercados de trabalho, dos produtos e dos padrões de consumo. É caracterizada pelo surgimento de setores de produção inteiramente novos, novas maneiras de fornecimento de serviços financeiros, novos mercados e, sobretudo, taxas altamente intensificadas de inovação comercial, tecnológica e organizacional (HARVEY, 1992, p.140).

As organizações passaram por um processo de reestruturação, no qual várias ocupações foram destruídas e outras novas surgiram. $\mathrm{O}$ emprego industrial foi reduzido em função da alta inserção de tecnologia, enquanto o setor de serviços se expandiu. O mercado de trabalho se flexibilizou e as relações de trabalho se precarizaram, com o aumento da ocupação por conta própria e da informalidade em geral. Nesse novo contexto, o emprego passou, então, a exigir novas habilidades da mão-de-obra. Passam a ser requisitos para o "novo" emprego: 
agilidade, abertura para mudanças, capacidade de assumir riscos continuamente e flexibilidade em relação às novas exigências do mercado. Tal conjuntura fez com que o trabalhador passasse a se preocupar com o acesso e a manutenção do emprego, ou seja, com sua empregabilidade.

A ênfase sobre as competências no lugar de qualificações (RAMOS, 2001; HIRATA, 1994) também intensifica a discussão sobre empregabilidade. Ao enfatizar características subjetivas, como criatividade e adaptabilidade, a noção de competência transfere do social para o individual a responsabilidade pela inserção profissional dos indivíduos. Para Paiva (2000, p.57), "a noção de competência parece trazer consigo uma outra mentalidade em relação ao trabalho e um outro conjunto de skills que começa com uma 'alfabetização tecnológica' e termina na naturalização da fragmentação, precarização e intensificação do trabalho".

Além da ênfase nas competências, o que se percebe também nas organizações de hoje é a exigência de maiores níveis de qualificação para a admissão de novos funcionários. Castel (1998) destaca que as organizações francesas vêm adotando esse caminho. Para o autor, esse fenômeno não corresponde a maiores imperativos técnicos. Trata-se, na verdade, de uma tendência das empresas a se "precaver contra futuras mudanças tecnológicas contratando jovens superqualificados, inclusive em setores de status pouco valorizados" (CASTEL, 1998, p.520). O autor destaca ainda que esse movimento desmotiva os jovens, aumentando sua mobilidade entre empregos precários, antes ocupados por jovens com pouca qualificação. $\mathrm{O}$ autor lembra que essa lógica ameaça invalidar as políticas que enfatizam a qualificação como o caminho mais glorioso para evitar o desemprego ou para sair dele. Sem dúvida, ainda é uma visão otimista da "crise" e que levou a pensar que, melhorando e multiplicando as qualificações, seria possível precaver-se contra a "não-empregabilidade".

Empregabilidade é vista comumente como a capacidade de adaptação da mão-de-obra diante das novas exigências do mundo do trabalho e das organizações. Não há, entretanto, um consenso em relação a esse ponto de vista. Diversos outros autores referem-se à empregabilidade como um discurso neoliberal, que transfere a responsabilidade pelo emprego, da sociedade e do Estado para o próprio trabalhador. Carrieri e Sarsur (2002) entendem a empregabilidade como uma estratégia adotada pela alta administração das empresas, no sentido de transferir da organização para o trabalhador a responsabilidade da não-contratação ou da demissão. Para Rodrigues (1997, p.228), o conceito de empregabilidade - conjugado com outros conceitos mais gerais como globalização, competitividade e reestruturação industrial - busca consolidar a "construção de uma rede discursivo-conceitual que tenta simultaneamente, por um lado, explicar uma nova etapa do desenvolvimento civilizatório e, por outro lado, facilitar as dores do parto do novo mundo do trabalho".

Como já foi destacado, o acesso ao emprego não pode ser determinado de forma simplista e restrita. A realidade mostra que várias são as explicações e os determinantes da empregabilidade. Segundo Paiva (2000, p.57), empregabilidade é uma "construção social mais complexa, na medida em que se descola das instituições formais e da experiência adquirida para considerar aspectos pessoais e disposições subjetivas, e para dar maior peso não apenas a aspectos técnicos, mas à socialização". É oportuno lembrar que essa visão de empregabilidade é bastante apropriada à realidade brasileira, marcada, segundo Freitas (1997), por um forte traço de personalismo. Para o autor, a sociedade brasileira é baseada em relações pessoais. Nesse sentido, não se pode imaginar que o acesso ao emprego no Brasil ocorra de modo impessoal e meritocrático, valorizando principalmente as variáveis ligadas ao esforço próprio individual, nomeadamente investimentos em capital humano (educação).

Civelli (1998) destaca que o acesso ao mercado de trabalho deve ser estudado de uma perspectiva diferenciada, na qual variáveis simbólicas, culturais, sociais e de valor estão se tornando fundamentais. Não se deseja, entretanto, com essa discussão, excluir as explicações existentes (capital humano) sobre os determinantes da empregabilidade. Apenas busca-se ampliar o entendimento acerca do fenômeno, a partir de outras visões que privilegiem também questões de ordem subjetiva e de enfoques ligados ao processo de socialização individual. Assim, serão apresentadas algumas das abordagens teóricas que podem explicar o acesso ao emprego. Cada uma delas destaca apenas alguns de seus fatores determinantes. É propósito deste artigo, mostrar essas diversas abordagens, possibilitando a construção de um modelo explicativo, com a finalidade de abranger aspectos relevantes para a empregabilidade individual, antes pouco explorados. 


\section{Determinantes da empregabilidade}

\section{Capital humano}

A abordagem econômica neoclássica propôs há muito uma explicação teórica para o mercado de trabalho. Tal abordagem ficou conhecida como "teoria do capital humano" (BECKER, 1964; MINCER, 1974). Para seus teóricos, quanto maior o estoque de capital humano de um indivíduo, maior sua produtividade marginal, mais elevado será o seu valor econômico no mercado de trabalho e, conseqüientemente, sua empregabilidade. De acordo com essa visão, Schultz $(1961 ; 1973)$ argumenta que as capacidades adquiridas dos agentes humanos (capital humano) devem ser vistas como uma fonte importante dos ganhos de produtividade. "Um investimento desta espécie (em capital humano) é o responsável pela maior parte do impressionante crescimento dos rendimentos reais por trabalhador" (SCHULTZ, 1973, p.32). Para o autor, são elementos inerentes ao capital humano individual: escolaridade, treinamento, experiência de trabalho, migração, condições de saúde e nutrição de uma pessoa, entre outros.

Neves e Fernandes (2002) destacam que dos fatores do capital humano, os três comumente mais estudados são: escolaridade, experiência de trabalho e migração. "O primeiro representa, sem dúvida, o principal fator de capital humano. O segundo representa uma proxy para o chamado on the job training. Finalmente, o terceiro é comumente utilizado em análises sobre o efeito do capital humano, pois representa, entre outras coisas, uma proxy para o nível de ambição dos indivíduos" (NEVES e FERNANDES, 2002, p.137).

A grande maioria das análises sobre os efeitos do capital humano no mercado de trabalho estão voltadas para o impacto desse tipo de capital nos salários dos indivíduos (CACCIAMALI e FREITAS, 1991; HALLER e SARAIVA, 1992; TELLES, 1993; FERNANDES, NEVES e HALLER, 1999). Poucos são os estudos voltados para o efeito dessa variável no acesso ao emprego (NEVES, DOURADO e FERNANDES, 1999; PRYOR e SCHAFFER, 1999).

Essa abordagem teórica é a mais comumente utilizada em estudos sobre o mercado de trabalho. Trata-se, contudo, de uma visão limitada sobre o assunto. Por ser produto do enfoque neoclássico da economia, a teoria do capital humano, ao tratar do mercado de trabalho, ignora aspectos sociais, que porventura estejam associados ao acesso ao emprego e à determinação de salários, por exemplo. Como já destacado, o mercado de trabalho é por demais complexo, o que não permite que seja analisado de modo simplista e reducionista. A equação de Mincer (1974), por exemplo, apresenta que o salário de um indivíduo é função de sua escolaridade, experiência de trabalho e migração. Tal explicação é bastante reduzida, pois "esquece" diversos outros fatores de ordem estrutural, influenciadores no processo de determinação do salário individual.

\section{Capital cultural}

A teoria do capital cultural foi desenvolvida por Bourdieu e seus colaboradores (BOURDIEU e PASSERON, 1977; BOURDIEU, 1979; BOURDIEU, 1987) e apresentada como um contraponto à visão funcionalista da teoria sociológica da modernização (PARSONS, 1974; LEVY, 1966) e à abordagem neoclássica da "teoria do capital humano". Segundo seus teóricos, o processo de expansão do acesso à educação, causado pela "modernização", não leva a uma maior equalização de oportunidades, uma vez que as famílias vindas de estratos sociais superiores continuam garantindo vantagens para seus descendentes através da transmissão do capital cultural.

Bourdieu (1979) destaca que a definição funcionalista das atribuições da educação - que ignora a contribuição que o sistema de ensino traz à reprodução da estrutura social, sancionando a transmissão hereditária do capital cultural - encontra-se, de fato, implicada numa definição do "capital humano" que não tem nada de humanista, pois não escapa ao economicismo e ignora, por exemplo, que o rendimento escolar da ação escolar depende do capital cultural previamente investido pela família e que o rendimento econômico e social do certificado escolar depende do capital social, que pode ser colocado a seu serviço.

Segundo Dumais (2002), capital cultural é compreendido como competência lingüística e cultural e como um amplo conhecimento da cultura que pertence aos membros de classes superiores; cultura que é encontrada 
menos freqüentemente entre as classes mais baixas. Kingston (2001), por sua vez, destaca que capital cultural não é um recurso geral disponível para todos, e sim propriedade da elite existente. A elite se beneficia em função de seus sinais culturais particulares, e não outros, serem recompensados.

Para Bourdieu (1987), estudantes com maior estoque de capital cultural, ou seja, estudantes oriundos de famílias com habilidades e preferências da cultura dominante, são mais capazes de decodificar as "regras do jogo" implícitas e estão melhor preparados para a adaptação e o desenvolvimento de habilidades culturais e preferências recompensadas nas escolas. "As diferentes ações pedagógicas que operam em uma formação social - vale dizer, tanto aquelas que as famílias das diferentes classes sociais exercem como a que a escola exerce - colaboram harmoniosamente na transmissão de um patrimônio cultural concebido como uma propriedade indivisa do conjunto da 'sociedade"' (BOURDIEU, 1987, p.297).

De acordo com essa perspectiva teórica, o estoque de capital cultural desenvolvido e transmitido no seio da família (com apoio do sistema educacional) garante a manutenção do status quo. Assim, mesmo que houvesse a universalização do ensino, aqueles indivíduos pertencentes a famílias detentoras de maior capital cultural seriam beneficiados.

Aschaffenburg e Maas (1997) destacam que a maioria das pesquisas sobre capital cultural o operacionalizam em termos de participação em selecionadas atividades de alto status cultural, como visitas a museus e teatros. Para os autores, capital cultural também vem sendo definido como atitudes e conhecimento a respeito dessas atividades.

A operacionalização do conceito de capital cultural vem ocorrendo de duas maneiras (ASCHAFFENBURG e MAAS, 1997; DUMAIS, 2002; ROSCIGNO e AINSWORTH-DARNELL, 1999): alguns estudos operacionalizam o termo a partir de dados referentes à participação em atividades de alto status cultural (visitas a museus e teatros, por exemplo), enquanto outras pesquisas utilizam as informações ligadas ao background familiar (nível educacional e ocupacional dos pais e renda familiar) como indicadores de capital cultural. Há ainda estudos que operacionalizam o termo utilizando ambos os caminhos, como a pesquisa realizada por De Graaf, De Graaf e Kraaykamp (2000) sobre capital cultural e seus efeitos no sistema educacional holandês. Estes autores, além de operacionalizarem capital cultural das duas maneiras, destacam, em seus resultados, que as variáveis de background familiar (especificamente, os anos de educação dos pais) estão correlacionadas positivamente com variáveis que indicam a participação dos pais em atividades de alto status cultural.

Sabe-se que o propósito inicial (e ainda mais utilizado) da teoria do capital cultural foi o de estudar a influência do background familiar (e das variáveis do capital cultural) nas conquistas acadêmicas. Dumais (2002) afirma que a maioria das análises tentam determinar se a noção de reprodução social de Bourdieu - baseada na transmissão de capital cultural entre gerações - é válida, e, sendo, determinar o papel desse capital no sistema educacional. Baseados nesse pressuposto, diversas investigações foram e vêm sendo realizadas (DIMAGGIO, 1982; DIMAGGIO e MOHR, 1985; KALMIJN e KRAAYKAMP, 1996; ASCHAFFENBURG e MAAS, 1997; ROSCIGNO e AINSWORTH-DARNELL, 1999; DE GRAAF, DE GRAAF e KRAAYKAMP, 2000; DUMAIS, 2002). São, sem dúvida, estudos relevantes, que exploraram empiricamente a importância do capital cultural no desempenho acadêmico. Tal foco, entretanto, não esgota as possibilidades de pesquisa sobre o tema. Não se pode imaginar que as variáveis ligadas ao capital cultural de um indivíduo influenciem apenas suas conquistas acadêmicas. Bourdieu (1987) e Collins (1979) destacam a relação entre o capital cultural, transmitido na família e na escola, e o mercado profissional. Para esses autores, o papel central da escola na sua relação com as empresas está baseado fundamentalmente na socialização para o trabalho. "O que é aprendido na escola tem maior relação com os padrões convencionais de sociabilidade e propriedade do que com habilidades instrumentais e cognitivas" (COLLINS, 1979, p.19).

As diferenças relativas ao capital cultural entre os indivíduos provocam impacto, inicialmente, no seu desempenho escolar, como já argumentado. Porém, ao ingressarem no mercado de trabalho, tais indivíduos irão trazer consigo um estoque de capital cultural, desenvolvido na família e "aperfeiçoado" no ambiente escolar, que será de extrema importância em sua vida profissional. A relação entre o estoque desse tipo de capital e o desempenho profissional individual mostra-se, desse modo, bastante plausível. No atual mundo do trabalho, 
centrado em competências e não mais apenas nas qualificações, o acesso ao emprego passa cada vez mais a ser determinado pelo capital cultural e social do indivíduo. Estudar a influência desses atributos nas chances de se obter um emprego formal passa a ser tarefa mais que necessária.

Infelizmente, apenas alguns poucos estudos foram realizados com o propósito de explorar a relação entre o capital cultural e as conquistas profissionais dos indivíduos (FERNANDES, 2001; ROSSETTI e TANDA, 2000; JOHNSON, FARRELL e STOLOFF, 1998; JOHNSON, BIENENSTOCK e STOLOFF, 1995). Rossetti e Tanda (2000) realizaram pesquisa interessante sobre o impacto do nível educacional dos pais nos salários dos indivíduos na Itália. Os resultados do estudo mostraram que a inclusão de variáveis referentes à escolaridade dos pais (indicador de capital cultural) aumenta o poder explicativo do modelo tradicional de capital humano (MINCER, 1974). Para as autoras, o efeito positivo registrado nos salários individuais, após modificação da equação minceriana, pode ser resultado do meio ambiente cultural da família, representado pela escolaridade dos pais, ou seja, resultado do capital cultural (background familiar) do indivíduo.

É de se esperar, portanto, que jovens oriundos de famílias com maior estoque de capital cultural levem vantagem não apenas em ambientes acadêmicos, mas também no mercado de trabalho, uma vez que é na família que alguns códigos de conduta e de relacionamento extremamente úteis para a atividade profissional são transmitidos aos jovens. Nesse sentido, indivíduos socializados em lares cujos pais têm níveis educacionais/culturais mais elevados e posições ocupacionais de maior destaque levam vantagem no mercado de trabalho em relação àqueles cujos pais possuam menor nível de escolaridade e posição ocupacional inferior.

\section{Capital social}

O conceito de capital social e sua aplicação, como bem destaca Fernandes (2001), apresentam-se como uma das mais difundidas linhas de análise no contexto atual das ciências sociais. Elementos como rede de relacionamentos e confiança são tópicos que estão na agenda do dia para pesquisadores em diversas áreas.

Após rever a literatura sobre o assunto, percebe-se a existência de duas correntes: uma que vê o capital social como algo pertencente a uma comunidade ou sociedade e outra que analisa esse tipo de capital como algo próprio de um indivíduo. A primeira corrente tende a enfatizar a confiança, enquanto a segunda destaca as redes de relacionamento como elementos do capital social.

Os principais representantes da primeira visão são Robert Putnam, principalmente com seu conhecido estudo sobre comunidade e democracia na Itália (PUTNAM, 2000) e James Coleman. Para Putnam (2000), capital social refere-se a aspectos da organização social, tais como redes, normas e confiança que facilitam coordenação e cooperação para benefícios mútuos. Ainda segundo o autor, capital social aumenta os benefícios do investimento em capital físico e capital humano.

Coleman $(1988 ; 1994)$ analisou o conceito de modo mais completo, e foi responsável, segundo Portes (1998), pela sua aplicação na sociologia americana. Para Coleman (1988, p.98; 1994, p.302), o capital social possui o seguinte significado:

(...) Capital social é definido pela sua função. Não é uma entidade simples, mas uma variedade de diferentes entidades com duas características em comum: todas elas consistem de alguns aspectos da estrutura social, todas facilitam certas ações dos atores - sejam pessoas ou atores corporativos - dentro da estrutura. Como outras formas de capital, capital social é produtivo, tornando possível atingir certos objetivos que na sua ausência não seriam alcançados. (...) Uma determinada forma de capital social que seja valiosa por facilitar certas ações pode ser até ou igualmente prejudicial para outras. Diferentemente de outras formas de capital, o capital social é próprio da estrutura de relações entre atores e no meio de atores $(\ldots)$

Segundo esses autores, capital social é algo que não pode ser internalizado pelo indivíduo, ou seja, é algo que existe na sociedade. 
A segunda visão sobre o tema, que acredita que capital social é algo de propriedade individual, tem como principais representantes Pierre Bourdieu, Mark Granovetter e Alejandro Portes. Esses autores destacam que o capital social é algo que pertence ao indivíduo e por ele pode ser utilizado de modo a produzir benefícios, inclusive, de ordem econômica (maiores salários, acesso a emprego etc). Segundo esses autores, cada um tem seu estoque de capital social e o utiliza para seu benefício.

É de Bourdieu (1980) a primeira análise contemporânea e sistemática sobre capital social. Para o autor, capital social é definido como o conjunto de recursos atuais ou potenciais que estão ligados pela posse de uma rede durável de relações mais ou menos institucionalizadas de interconhecimento e de reconhecimento mútuo. Em outros termos, ligados à vinculação a um grupo, como conjunto de agentes que não são somente dotados de propriedades comuns, mas também unidos por ligações permanentes e úteis. Nesse sentido, o volume do capital social que um agente individual possui depende da extensão da rede de relações que ele pode efetivamente mobilizar e do volume de capital (econômico, cultural ou simbólico) que é posse exclusiva de cada um daqueles a quem está ligado.

Para Portes (1998), as fontes e consequiências do capital social são as mais diversas possíveis. Segundo o autor, estudos empíricos sobre o tema têm incluído a aplicação do conceito como "preditor" do desempenho acadêmico, desenvolvimento intelectual da criança, empregabilidade e mobilidade ocupacional, delinquiência juvenil e sua prevenção.

Após revisão de literatura, Portes (1998, p.9) distinguiu três funções básicas do capital social: “(a) como uma fonte de controle social, (b) como uma fonte de suporte familiar; (c) como uma fonte de benefícios, por meio de redes extrafamiliares". O autor, ao adotar posição semelhante a de Bourdieu, destaca que, de longe, essa última função é, comumente, a mais atribuída ao capital social.

Um dos primeiros autores a demonstrar e explorar os efeitos do capital social no mercado de trabalho foi Mark Granovetter. Seu estudo (GRANOVETTER, 1995), na década de 1970, sobre como 282 homens em Newton, Massachusetts (EUA) conseguiram seus empregos é um clássico que comprova a relevância do capital social como determinante da empregabilidade.

Outros estudos, mais recentemente, também vêm destacando essa relação (PODOLNY e BARON, 1997; FERNANDEZ e WEINBERG, 1997; DE GRAAF e FLAP, 1988; FERNANDEZ, CASTILLA e MOORE, 2000; PETERSEN, SAPORTA e SEIDEL, 2000; MAMAN, 2000). De modo geral, essas análises exploram o papel da rede de relacionamentos de um indivíduo no acesso ao emprego e no processo de mobilidade ocupacional, em diversos países. Lamentavelmente, poucos estudos têm sido realizados no Brasil, a respeito dessa função e aplicação do capital social.

Petersen, Saporta e Seidel (2000) pesquisaram o impacto causado pelo sexo, pela raça e pelas redes sociais no processo seletivo de uma média organização de alta tecnologia nos EUA. Em seus resultados concluíram que, com relação ao gênero, o processo é inteiramente meritocrático. Já para as minorias étnicas, o processo seletivo se mostrou em parte meritocrático e em parte dependente de redes sociais. Os autores acreditam que as minorias étnicas têm desvantagens no processo de seleção, pois carecem de acesso ou utilizam de forma menos eficiente as redes de relacionamento, que, conforme resultados do estudo, são relevantes para o acesso ao emprego (GRANOVETTER, 1995, p.151).

O estudo de Fernandez, Castilla e Moore (2000), em uma grande firma de call center americana, destaca o papel do capital social, enfatizando a importância que a ele é dada pelos empregadores. Os autores afirmam que estes constantemente consideram as redes sociais de relacionamento, no processo de seleção de novos empregados. $^{2}$

\footnotetext{
${ }^{2}$ Em estudo anterior Fernandez e Weinberg (1997) analisam o impacto, no processo seletivo de um banco de varejo nos EUA, de um indivíduo ter sido indicado ao cargo por um funcionário da empresa. Os resultados do estudo mostram que os indicados têm vantagens nas entrevistas e em outras etapas do processo seletivo.
} 
Tal conclusão enriquece bastante o debate teórico da sociologia econômica sobre a natureza inserida (embedded nature) do processo econômico, como bem destaca Granovetter (1985). De acordo com o autor, a ação econômica - nesse caso, a busca e o processo de seleção para um emprego - deve ser vista e estudada como algo inserido e influenciado pela estrutura social da qual faz parte. Importa destacar que tal perspectiva supera $\mathrm{o}$ foco tradicional na estrutura e em elementos técnicos, enfatizando o aspecto dinâmico dos relacionamentos interpessoais. Essa abordagem pode muito bem ser vista como uma solução para o impasse entre estrutura e agência.

Como visto, o conceito de capital social é bastante amplo, e seu entendimento na literatura, bastante diverso. Apesar dessa variedade de concepções sobre o tema, é possível identificar dois elementos comuns: a confiança e a rede de relacionamentos. O segundo elemento é o mais utilizado nas pesquisas que exploram a relação entre capital social e empregabilidade, uma vez que se costuma definir capital social como a posse e a utilização de uma rede de relacionamentos. A operacionalização desse termo tem sido feita por alguns autores a partir da utilização de variáveis indicadoras da participação dos indivíduos em grupos e organizações. Schiff (2000) afirma que a participação em grupos e em organizações cívicas formais é um aspecto do capital social.

Vale lembrar que a operacionalização do capital social a partir da participação em associações destaca a importância dos laços fracos (strength of weak ties), termo apresentado por Granovetter (1973) para se referir ao poder de influência indireta dos relacionamentos fora do círculo imediato da família e dos amigos próximos (strong ties). Para o autor, tais relacionamentos, baseados em laços fracos (indiretos) - como aqueles encontrados entre os indivíduos participantes de um grupo ou associação -, são importantes, pois conectam os indivíduos a uma maior gama de informações e conhecimentos relativos a empregos. "Apesar dos amigos próximos de um indivíduo serem mais motivados a ajudá-lo, os laços fracos estão estruturalmente localizados de modo a serem mais úteis no processo de busca por emprego" (GRANOVETTER, 1995, p.148).

Assim, baseado na teoria do capital social, é de se esperar que o fato de um indivíduo pertencer a grupos ou associações - ou seja, a posse e a utilização da rede de relacionamentos (capital social) aí desenvolvida por esse indivíduo- afete positivamente a probabilidade desse indivíduo estar empregado.

\section{Modelo explicativo}

O modelo proposto por este artigo (ver figura 1) visa apresentar, baseado em uma profunda discussão teórica, determinantes da empregabilidade individual, em um contexto pós-fordista, no qual aspectos subjetivos são exigidos da força de trabalho. Como já foi destacado, o modelo amplia a abordagem corrente sobre o assunto (teoria do capital humano), ao acrescentar variáveis não-meritocráticas ligadas ao capital cultural e social de um indivíduo. $\mathrm{O}$ modelo indica, logo abaixo de cada variável dependente, a operacionalização da variável. Desse modo, além de propor novos elementos explicativos da probabilidade de um indivíduo estar empregado, são apresentadas sugestões, baseadas em literatura internacional, para que tais elementos possam ser pesquisados. 


\section{Figura 1}

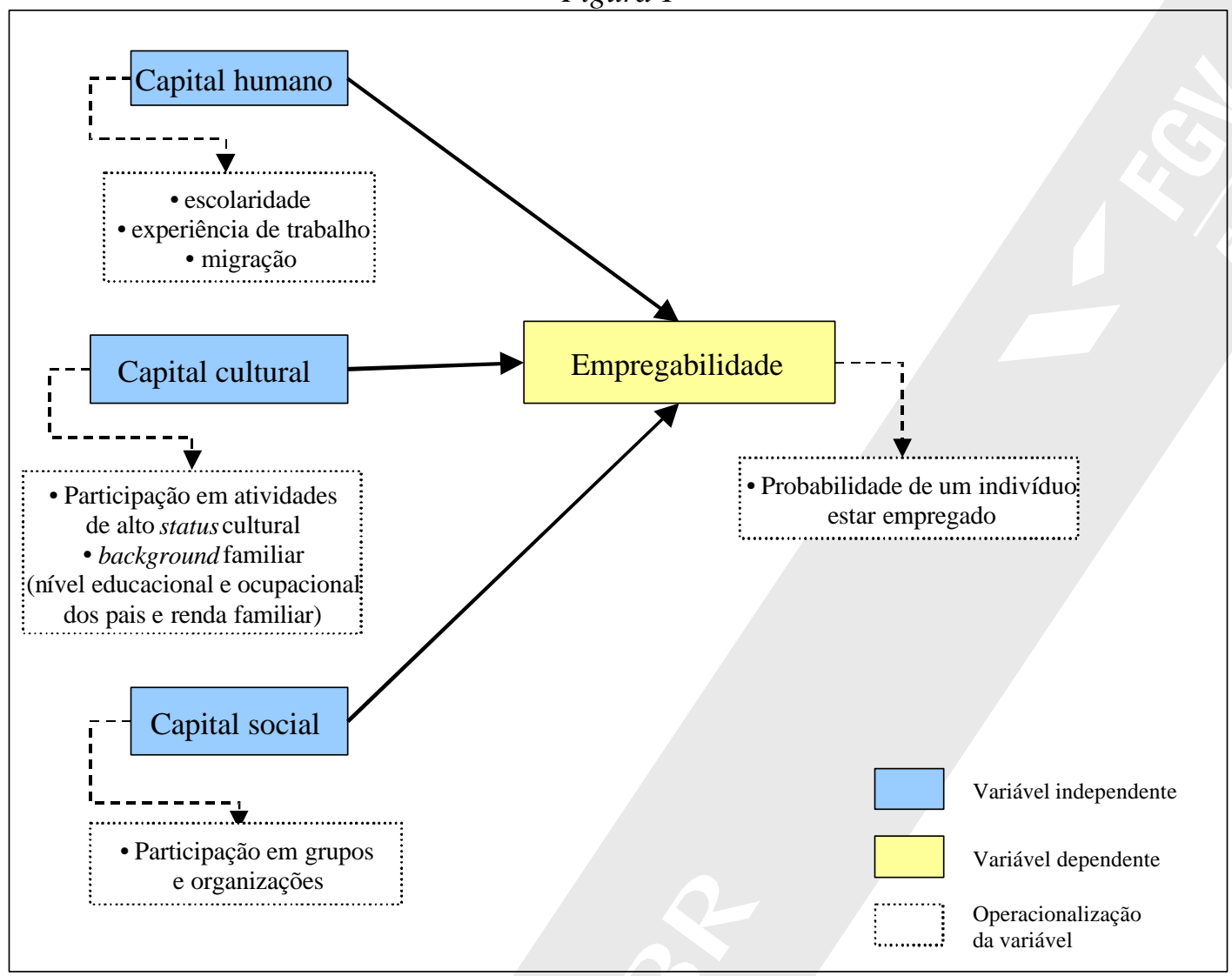

\section{Operacionalização das variáveis}

Em relação ao capital humano, Neves e Fernandes (2002) destacam que sua operacionalização é feita mediante utilização de três fatores principais: escolaridade (medida em anos de estudo completados com sucesso), experiência de trabalho (medida em anos) e migração (migrou/não migrou). "O primeiro representa, sem dúvida, o principal fator de capital humano. O segundo representa uma proxy para o chamado on the job training. Finalmente, o terceiro é comumente utilizado em análises sobre o efeito do capital humano, pois representa, entre outras coisas, uma proxy para o nível de ambição dos indivíduos" (NEVES e FERNANDES, 2002, p.137). Essas três variáveis, segundo a abordagem econômica neoclássica (BECKER, 1964; MINCER, 1974), estão ligadas às capacidades adquiridas dos indivíduos, e seu acúmulo garante a este um maior valor econômico no mercado de trabalho (em função de uma maior produtividade marginal) e conseqüentemente uma maior empregabilidade.

A operacionalização do capital cultural, por sua vez, vem sendo feita de duas maneiras (ASCHAFFENBURG e MAAS, 1997; DUMAIS, 2002; DE GRAAF, DE GRAAF e KRAAYKAMP, 2000; ROSCIGNO e AINSWORTH-DARNELL, 1999): por meio da utilização de dados ligados à participação em atividades de alto status cultural (visitas a museus e teatros, por exemplo) e por meio de informações ligadas ao background familiar (nível educacional e ocupacional dos pais e renda familiar). De Graaf, De Graaf e Kraaykamp (2000), em estudo sobre o capital cultural e seus efeitos no sistema educacional holandês, utilizaram ambas operacionalizações e, em seus resultados, destacaram que as variáveis de background familiar (especificamente os anos de educação dos pais) estão correlacionadas positivamente com variáveis que indicam a participação dos pais em atividades de alto status cultural. 
Por sua vez, o capital social é definido, por exemplo, como a posse e utilização de uma rede de relacionamentos. Sua operacionalização, nesse sentido, vem sendo feita a partir de informações referentes à participação dos indivíduos em grupos e organizações. Schiff (2000) afirma que a participação em grupos e em organizações cívicas formais é um aspecto do capital social. Assim, a operacionalização do termo, a partir de tais informações, mostra-se plausível e possível. Como visto, tal procedimento destaca também a importância dos laços fracos - relacionamentos fora do círculo imediato da família e dos amigos próximos (GRANOVETTER, 1973). Esses relacionamentos, baseados em laços fracos (indiretos), como aqueles encontrados entre os indivíduos participantes de um grupo ou associação, são importantes, pois conectam os indivíduos a uma maior gama de informações e conhecimentos relativos a empregos, criando impacto em sua empregabilidade.

A variável dependente, empregabilidade, é comumente definida como a capacidade de adaptação da mão-deobra diante das novas exigências do mundo do trabalho e das organizações. Sua operacionalização aqui proposta está baseada na obtenção de dados referentes à probabilidade de um indivíduo estar empregado. Tais informações podem ser obtidas, por exemplo, em fontes secundárias (IBGE).

\section{Conclusões, limitações e recomendações para estudos futuros}

Este artigo procurou apresentar um modelo explicativo da empregabilidade, no contexto da flexibilidade organizacional, com base em três abordagens teóricas: teoria do capital humano, teoria do capital cultural e teoria do capital social. Como já destacado, a construção do modelo de empregabilidade, baseado nessas três teorias amplia a discussão comum sobre o tema (teoria do capital humano), tornando o modelo mais próximo da realidade organizacional, na qual variáveis não-meritocráticas, de ordem subjetiva, são exigidas dos trabalhadores pelo mercado.

A visão mais ampla sobre a empregabilidade individual, aqui proposta, vem preencher uma lacuna, tanto na literatura nacional quanto na estrangeira - pela pequena quantidade de estudos a respeito de outras explicações, diferentes das relacionadas ao capital humano - sobre fenômenos do mercado de trabalho. No entanto, algumas exceções devem ser destacadas. Um importante estudo foi o desenvolvido por Rossetti e Tanda (2000). As autoras pesquisaram o impacto do nível educacional dos pais nos salários dos indivíduos na Itália. Os resultados mostraram que a inclusão de variáveis referentes à escolaridade dos pais (variável indicadora de capital cultural) aumenta o poder explicativo do modelo tradicional de capital humano (MINCER, 1974).

Granovetter, na década de 1970, também pesquisou o mercado de trabalho, a partir de diferentes abordagens teóricas. Seu estudo à época (GRANOVETTER, 1995), sobre como 282 homens em Newton, Massachusetts (EUA) conseguiram seus empregos, é um clássico que comprova a relevância do capital social como determinante da empregabilidade.

Os resultados dessas pesquisas mostram que a sociedade e as organizações, por mais que os anseios modernos desejem comprovar, não são tão meritocráticas. A abordagem neoclássica da economia (teoria do capital humano) já comprovou por diversas vezes a relevância e a valorização dada pelo mercado de trabalho às capacidades adquiridas pelos indivíduos, tais como escolaridade e experiência de trabalho. O que já se percebe, entretanto, é a existência de outros fatores, também valorizados pelas organizações, no processo de seleção, promoção e determinação de salários, principalmente, em um ambiente marcado pela flexibilidade organizacional.

A conclusão de que elementos ligados ao capital cultural e social de um indivíduo são relevantes no mercado de trabalho também enriquece bastante o debate teórico da sociologia econômica sobre a natureza "inserida" (embedded nature) do processo econômico, como bem destaca Granovetter (1985). Sobre esse assunto, também se destaca a visão de Polanyi (1980). O autor analisa a crise econômica e política dos anos 1930-1945, reposicionando o lugar da economia na sociedade. Para ele, o período pós-1930 representa "o grande retorno": a economia não pode ser estudada em um vácuo social, como faziam os liberais econômicos. 
Há de se destacar também algumas limitações neste artigo. A proposição de um modelo explicativo é sempre limitada, e não consegue abarcar a riqueza de casos especiais. Não se buscou, neste estudo, apresentar uma explicação única e superior sobre a empregabilidade dos indivíduos. A intenção da proposição deste modelo foi a ampliação da discussão corrente sobre empregabilidade, para permitir um melhor conhecimento acerca das linhas gerais do fenômeno. A discussão teórica aqui apresentada e direcionada para o fenômeno visa estimular a continuidade dos estudos sobre o assunto. Pesquisas futuras, utilizando dados quantitativos, bem como abordagens qualitativas, irão certamente permitir um maior aprofundamento sobre o tema.

A contribuição deste artigo reside na apresentação de uma nova discussão acerca de outros elementos valorizados atualmente pelo mercado de trabalho; especialmente aqueles importantes para a empregabilidade. Espera-se que tal debate sirva de base para diversos estudos empíricos sobre o mercado de trabalho, principalmente no Brasil, um país de traços conhecidamente personalistas (FREITAS, 1997), onde são destacadas as relações pessoais.

Essa visão mais aprofundada sobre os elementos determinantes da empregabilidade pode contribuir para o redirecionamento das políticas públicas voltadas para o mercado de trabalho brasileiro, ao sugerir que os investimentos em educação não são os únicos que podem favorecer o indivíduo na busca pelo emprego. $\mathrm{O}$ posicionamento apresentado por este artigo também contribui para a área de recursos humanos, pois explicita, com base em uma profunda discussão teórica, a importância atribuída pelas organizações a aspectos nãomeritocráticos, como aqueles ligados ao capital cultural e social do indivíduo. Tal conclusão pode reorientar, por exemplo, práticas de recrutamento e seleção nas organizações, assim como pode indicar aos indivíduos o que realmente se privilegia no mercado de trabalho. 


\section{Referências bibliográficas}

ASCHAFFENBURG, K.; MAAS, I. Cultural and educational careers: the dynamics of social reproduction. American Sociological Review, V.62, p.573-587, Aug. 1997.

BECKER, G. Human capital: a theoretical and empirical analysis, with special reference to education. Nova York: NBER/Columbia University Press, 1964.

BOURDIEU, P. Les trois états du capital culturel. Actes de la Recherche en Sciences Sociales, Paris, n.30, p.3-6, nov. 1979.

. Le capital social - notes provisoires. Actes de la Recherche en Sciences Sociales, Paris, n.31, p.2-3, jan. 1980.

Reprodução cultural e reprodução social. In: MICELI S. (Org.). A economia das trocas simbólicas. 2.ed. São Paulo: Editora Perspectiva, 1987.

; PASSERON, J-C. Reproduction in education, society and culture. London: Sage Publications, 1977.

BURT, R. S. The network structure of social capital. In: SUTTON, R.; STAW, B. Research in Organizational Behavior. Greenwich, CT: JAI Press, 2000, v.22.

CACCIAM ALI, M.; FREITAS, P. Do capital humano ao salário eficiência: uma aplicação para analisar os diferenciais de salários em cinco ramos manufatureiros da Grande São Paulo. ENCONTRO NACIONAL DE ECONOMIA, 19., 1991. Anais..., 1991. v.3, p.213- 222.

CARRIERI, A.; SARSUR, A. M. Percurso semântico do tema empregabilidade: um estudo de caso em uma empresa de telefonia. ENCONTRO NACIONAL DE PÓS- GRADUAÇÃO EM ADM INISTRAÇÃO - Enampad, 26., 2002, Salvador. Anais... Salvador: Anpad, 2002. 1 CD.

CASTEL, R.. As metamorfoses da questão social: uma crônica do salário. Petrópolis, RJ : Vozes, 1998.

CASTELLS, M. A sociedade em rede. A era da informação: economia, sociedade e cultura. 1.ed. São Paulo: Paz e Terra, 1999. v.1.

CIVELI, F. Personal competencies, organizational competencies and employability. Industrial and Commercial Training, Guilsborough, v.30, n.02, p.48-52, 1998

COLEMAN, J. S. Social capital in the creation of human capital. American Journal of Sociology, v.94, 1988. Supplement, p.S95-S120.

. Foundations of social theory. Cambridge, MA: Belknap Press of Harvard University Press, 1994.

COLLINS, R. The credential society: an historical sociology of education and stratification. New York: Academic Press, 1979.

DE GRAAF, N. D.; DE GRAAF, P. M.; KRAAYKAMP, G. Parental cultural capital and educational attainment in the Netherlands: a refinement of the cultural capital perspective. Sociology of Education, v.73, p.92-111, Apr. 2000.

; FLAP, H. D. 'With a little help from my friends': social resources as an explanation of occupational status and income in West Germany, The Netherlands and the United States. Social Forces, v.67, n.02, p.452-472, Dec. 1988.

DIMAGGIO, P. J. Cultural capital and schooling success: the impact of status culture participation on the grades of U.S. high school students. American Sociological Review, v.47, p.189-201, 1982.

; MOHR, J. Cultural capital, educational attainment and marital selection. American Journal of Sociology, v.90, p.1231-1261,

DUM AIS, S. A. Cultural capital, gender and school success: the role of habitus. Sociology of Education, v.75, p.44-68, Jan. 2002.

FERNANDES, A. S. A. O conceito de capital social e sua aplicação na análise institucional e de políticas públicas. ENCONTRO NACIONAL DE PÓS- GRADUAÇÃO EM ADMINISTRAÇÃO - Enampad, 25., 2001, Campinas. Anais... Campinas: Anpad, 2001. 1 CD.

FERNANDES, D. C. Capital humano, capital cultural e a determinação da posição gerencial.

ENCONTRO NACIONAL DE ENGENHARIA DE PRODUÇÃO - Enegep, 2001. Anais..., 2001.

; NEVES, J. A.; HALLER, A. Credencialismo, correspondência ou capital humano? Como a escolaridade af eta a determinação de cargos e salários de trabalhadores da indústria de transformação no Brasil. Estudos Avançados em Administração, v.7, n.1, p.1033-1048, 1999.

FERNANDEZ, R. M.; CASTLLA, E. J.; MOORE, P. Social capital at work: networks and employment at a phone center. American Journal of Sociology, v.105, n.5, p.1288-1356, Mar. 2000. Dec. 1997.

WEINBERG, N. Sifting and sorting: personal contacts and hiring in a retail bank. American Sociological Review, v.62, p.883-902,

FERRETTI, C. J. "Formação profissional e reforma do ensino técnico no Brasil: anos 90". Educação \& Sociedade, Campinas, SP, ano 18, $n^{\circ}$ 59, pp. 225-269, ago. 1997. 
FREITAS, A. B. Traços brasileiros para uma análise organizacional. In: M OTTA, F. P.; CALDAS, M. (Org.). Cultura organizacional e cultura brasileira. São Paulo: Atlas, 1997.

FRIGOTTO, G. Educação e formação humana: ajuste neoconservador e alternativa democrática". In: GENTILI, P.; DA SILVA, T. (Org.). Neoliberalismo, qualidade total e educação: visões críticas. 5.ed. Petrópolis, RJ : Vozes, 1997.

GRANOVETIER, M. The strength of weak ties. American Journal of Sociology, v.78, n.6, p.1360-1380, May 1973. $\overline{19} \overline{8} \overline{5}$

Economic action and social structure: the problem of embeddedness. American Journal of Sociology, v.91, n.3, p.481-510, Nov.

Getting a job: a study of contacts and careers. 2.ed. Chicago: The University of Chicago Press, 1995.

HALLER, A.; SARAIVA, H. The income effects of education in a developing country: Brazil - 1973 and 1982. In: ALTHAUSER, R.; WALLACE, M. (Org.). Research in Social Stratification and Mobility, v11, p.295-336, 1992.

HARVEY, D. Condição pós- moderna: uma pesquisa sobre as origens da mudança cultural. 5.ed. São Paulo: Loyola, 1992.

HIRATA, H. Da polarização das qualificações ao modelo da competência. In: FERRETT, C. J. et al. (Org.). Novas tecnologias, trabalho e educação: um debate multidisciplinar. 7.ed. Petrópolis, RJ : Vozes, 1994.

JOHNSON J r., J. H.; BIENENSTOCK, E. J.; STOLOFF, J. A. An empirical test of the cultural capital hypothesis. The Review of Black Political Economy, v.23, n.4, p.7-27, spring 1995.

; FARRELL J r., W. C.; STOLOFF, J. A. The social declining and economic fortunes of African American males: a critical assessment of four perspectives. The Review of Black Political Economy, v.25, n.4, p.17-40, spring 1998.

KALMIJN, M.; KRAAYKAMP, G. Race, cultural capital and schooling: an analysis of trends in the United States. Sociology of Education, V.69, p.22-34, Jan. 1996.

KINGSTON, P. W. The unfulfilled promise of cultural capital theory. Sociology of Education, extra issue, p.88- 99, 2001.

LEVY, M. Modernization and the structure of societies. Princeton, NJ : Princeton University Press, 1966.

MAMAN, D. Who accumulates directorships of big business firms in Israel?: organizational structure, social capital and human capital. Human Relations, v.53, n.5, p.603-629, 2000.

MINCER, J. Schooling, experience and earnings. Nova Iorque: NBER/Columbia University Press, 1974.

NEVES, J. A.; DOURADO, D. P.; FERNANDES, D. C. Compreendendo a questão da empregabilidade formal no Brasil. Recife: Departamento de Ciências Administrativas - UFPE, 1999. Mimeografado.

; FERNANDES, D. C. Estrutura ocupacional, autoridade gerencial e determinação de salários em organizações fordistas: 0 caso da indústria de transformações no Brasil. RAC - Revista de Administração Contemporânea, v.06, n.1, p.127-140, jan./abr. 2002.

PAIVA, V. Qualificação, crise do trabalho assalariado e exclusão social. In: GENTILI, P.; FRIGOTTO, G. (Org.). A cidadania negada: políticas de exclusão na educação e no trabalho. 1.ed. Buenos Aires: Clacso, 2000. p.49-64.

PARSONS, T. 0 sistema das sociedades modernas. São Paulo: Pioneira, 1974.

PASTORE, J.; SILVA, N. V. Mobilidade social no Brasil. São Paulo: Makron Books, 2000.

PETERSEN, T; SAPORTA, I.; SEIDEL, M.-D. L. Offering a job: meritocracy and social networks. American Journal of Sociology, v.106, n.3, p.763-816, Nov. 2000

PIORE, M.; SABEL, C. The second industrial divide: possibilities for prosperity. Nova York: Basic Books, 1984.

POCHMANN, M. 0 emprego na globalização: a nova divisão internacional do trabalho e os caminhos que o Brasil escolheu. 1.ed. São Paulo: Boitempo Editorial, 2001.

PODOLNY, J. M.; BARON, J. N. Resources and relationships: social networks and mobility in the workplace. American Sociological Review, V.62, p.673-693, Oct. 1997.

POLANYI, K. A grande transformação: as origens da nossa época. Rio de Janeiro: Campus, 1980.

PORTES, A.. Social capital: its origins and applications in modern sociology. Annual Review of Sociology, v.24, p.01-24, 1998.

PRYOR, F.; SCHAFFER, D. Who is not working and why: employment, cognitive skills, wages and the changing U.S. labor market. Nova York: Cambridge University Press, 1999.

PUTNAM, R. D. Comunidade e democracia: a experiência da Itália moderna. 2.ed. Rio de Janeiro: Editora FGV, 2000.

RAM OS, M. N. Pedagogia das competências: autonomia ou adaptação? São Paulo: Cortez, 2001.

RODRIGUES, J. Da teoria do capital humano à empregabilidade: um ensaio sobre as crises do capital e a educação brasileira. Trabalho \&

Educação - Revista do Nete, Belo Horizonte, n.2, p.215-230, ago./dez. 1997. 
ROSCIGNO, V.J .; AINSWORTH-DARNELL, J. W. Race, cultural capital, and educational resources: persistent inequalities and achievement returns. Sociology of Education, v.72, p.158-178, July 1999.

ROSSETTI, S.; TANDA, P. Human capital, wages and family. Labour, v.14, n.1, p.5-34, 2000.

SANTOS, J. A. F. Estrutura de posições de classe no Brasil: mapeamento, mudanças e efeitos na renda. Belo Horizonte: Editora UFM G; Rio de Janeiro: Iuperj, 2002.

SCHIFF, M. W. Labor market integration in the presence of social capital. Washington, DC: World Bank, 2000.

SCHULTZ, T. W. Investment in human capital. American Economic Review, v 51, p.1-17, Mar. 1961.

0 capital humano: investimentos em educação e pesquisa. Rio de Janeiro: Zahar Editores, 1973.

SINGER, P. Globalização e desemprego: diagnóstico e alternativas. 4.ed. São Paulo: Contexto, 2000.

TELLES, E. Urban labor market segmentation and income in Brazil. Economic Development and Cultural Change, v.41, p.231-249, 1993. 